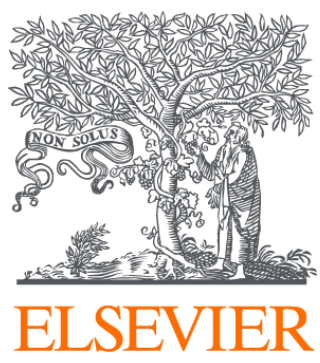

Since January 2020 Elsevier has created a COVID-19 resource centre with free information in English and Mandarin on the novel coronavirus COVID-

19. The COVID-19 resource centre is hosted on Elsevier Connect, the company's public news and information website.

Elsevier hereby grants permission to make all its COVID-19-related research that is available on the COVID-19 resource centre - including this research content - immediately available in PubMed Central and other publicly funded repositories, such as the WHO COVID database with rights for unrestricted research re-use and analyses in any form or by any means with acknowledgement of the original source. These permissions are granted for free by Elsevier for as long as the COVID-19 resource centre remains active. 


\title{
Monthly suicide rates during the COVID-19 pandemic: Evidence from Japan
}

\author{
Gerardo Ruiz Sánchez \\ Trinity College, Economics Department, 300 Summit St., Hartford, CT 06106, United States of America
}

\section{A R T I C L E I N F O}

\section{Article history:}

Received 16 January 2021

Received in revised form 24 July 2021

Accepted 27 July 2021

Available online 30 July 2021

\section{JEL classification:}

I10

I14

J38

Keywords:

COVID-19

Suicide

Suicide rates

Japan

\begin{abstract}
A B S T R A C T
This paper uses 2018-2020 prefecture-month-year, gender-month-year, and age group-month-year level data on suicide rates in Japan to document how suicide rates are evolving during the COVID-19 pandemic. I use a monthly event study design to study changes in suicide rates surrounding Japan's COVID-19 state of emergency and to trace out monthly changes in suicide rates during the first 11 months of 2020 relative to 2018-2019. I find that monthly suicide rates during the pandemic started increasing meaningfully in June-July 2020. I find that women experienced greater increases in suicide rates than men, relative to their 2018-2019 average suicide rate, and that women experienced the largest increase in suicide rates in October 2020. I also find descriptive evidence that in terms of suicide, individuals under 30 years old were faring worse during the pandemic.
\end{abstract}

(c) 2021 Elsevier B.V. All rights reserved.

\section{Introduction}

Suicide is a global health issue. According to the World Health Organization, close to 800,000 people die from suicide every year (WHO, 2019). Moreover, there is increasing concern among public health officials that suicide rates will increase during the COVID19 pandemic. In this paper, I use 2018-2020 prefecture-monthyear, gender-month-year, and age group-month-year level data on suicide rates in Japan to document how suicide rates are evolving during the COVID-19 pandemic. I use a monthly event study design to study changes in suicide rates surrounding Japan's COVID-19 state of emergency and to trace out monthly changes in suicide rates during the first 11 months of 2020 relative to 2018-2019.

I find that monthly suicide rates during the pandemic started increasing meaningfully in June-July, with an important increase in October. This result contrasts with the findings of other researchers who use data from other countries and who do not find evidence of an increase in suicides during the pandemic. For example, research using data from Massachusetts finds stable rates of suicide deaths during the stay-at-home advisory (Faust et al., 2021a). More recent work using national-level data finds that suicide deaths in the United States were statistically significantly lower than projected (Faust et al., 2021b). Additionally, Greece did not show an increase in suicides during the first wave of COVID-19 (Vandoros et al., 2020).

\footnotetext{
E-mail address: gerardo.ruizsanchez@trincoll.edu.
}

In contrast with these cited studies, I am also able to analyze how suicide rates vary across gender groups and across age groups. I find that women experienced greater increases in suicide rates relative to their 2018-2019 average suicide rate when I compare Japanese men and women. This gender difference finding also contrasts with previous work using data from Peru, which finds that during the first week of Peru's lockdown, suicides for both men and women experienced a slight decrease compared to previous years, followed by a return to previous levels in the post-lockdown period (Calderon-Anyosa et al., 2021). I also find descriptive evidence that in Japan, individuals under 30 years old were faring worse during the pandemic in terms of suicide.

This paper contributes to the literature that studies how social and economic circumstances affect suicide rates by documenting how they are evolving during a pandemic (Becker and Woesmann, 2018; Campaniello et al., 2017; Cutler et al., 2001; Daly et al., 2013; Lenhart, 2019; Ludwig et al., 2009; Stevenson and Wolfers, 2006; Christian et al., 2019; Dow et al., 2020).

\section{Descriptive results using prefecture-level data}

I collected prefecture-month-year level data on suicide counts from January 2018 to November 2020 reported by Japan's National Police Agency. I also collected prefecture-year level population estimates for years 2018-2020 from the Statistical Handbooks of Japan. I combine both datasets to compute prefecturemonth-year level suicide rates (number of suicides per 100,000). 


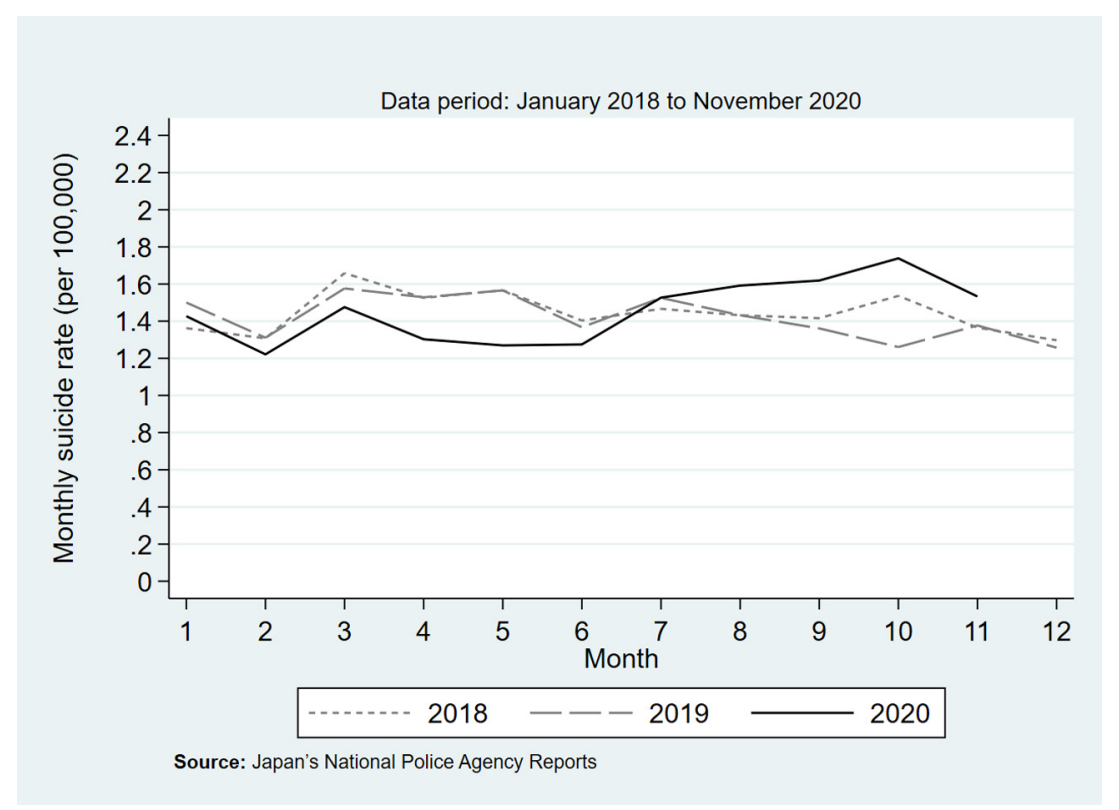

Fig. 1. Monthly suicide rate average (over the 47 prefectures).

Fig. 1 plots, for each month and year in the data, the average of the monthly suicide rates across the 47 prefectures in Japan. Fig. 1 depicts how this average evolves across each month within each year and enables us to compare the same month across different years. Interestingly, the data show that this average did not increase, relative to previous years, immediately after the COVID-19 pandemic started. For example, if we compare 2019 and 2020, the averages for February-June 2020 are below those during the same months in 2019; the graphs cross in July and then the averages for 2020 are above those of 2019 during August-November. A similar pattern emerges if we compare 2018 and 2020.

\subsection{Monthly event study model using prefecture-level data}

I estimate the following event study model to document when changes in suicide rates started and to study changes in suicide rates in a more agnostic and rigorous way:

$$
\begin{aligned}
S R_{\text {pmy }}= & \sum_{\text {month=January }}^{\text {November }} \beta_{\text {month }} * I(m=\text { month and } m \text { belongs to 2020) } \\
& +\lambda_{p}+\mu_{m}+\theta_{y}+\varepsilon_{\text {pmy }}
\end{aligned}
$$

where $S R_{p m y}$ is the monthly suicide rate for prefecture $p$ in month $m$ and year $y$. To account for seasonal trends and unobserved differences across prefectures I include prefecture fixed effects $\lambda_{p}$, month fixed effects $\mu_{m}$, and year fixed effects $\theta_{y}$ in the regression. The coefficients of interest are the beta coefficients $\beta_{\text {month }}$ pertaining to the indicator functions that take a value of one if month $m$ belongs to year 2020 and month $m$ is equal to the applicable "month" in the sum. I exclude the month of March since April is the month the state of emergency was declared in Japan, and April is the month when the mobility index was at its lowest level during the pandemic (see Appendix A for details about the mobility index). The excluded baseline period also includes the 2018-2019 period as a reference for 2020. I use data from the months of January-November in 2018-2020 to estimate this event study model and cluster standard errors at the prefecture level.
Fig. 2 presents the estimated event study coefficients of interest along with bootstrapped confidence intervals. These coefficients trace out monthly changes in suicide rates during the first 11 months of 2020 relative to 2018-2019. The point estimates for June, July, and August mark a clear break with the coefficients' downward trend and show suicide rates increasing. The estimated changes in the second half of the year are meaningful. For example, the average monthly suicide rate for 2018-2019 was 1.43 , and the estimated change for October 2020 is 0.48 , which is equal to $31.4 \%$ of the $2018-2019$ mean. The estimated change for July 2020 is 0.17 , which is equal to $11.8 \%$ of the 1.43 mean.

It is important to emphasize that the results in this section account for seasonal changes and for unobserved heterogeneity across prefectures since I include fixed effects in the regression. Therefore, there is evidence that monthly suicide rates during the pandemic started increasing meaningfully around June-July, with an important increase in October. These results are confirmed in Appendix B, where I also report results using absolute suicide counts as the outcome variable in the event study regression while controlling for the population size of each prefecture. In the next section, I study suicide rates for men and women.

\section{Suicide rates by gender group}

I collected gender-month-year level data on suicide counts for years 2018-2020 reported by Japan's National Police Agency and combined them with gender-year level population estimates for years 2018-2020 to compute gender-month-year level suicide rates. Fig. 3 plots these data. The average suicide rate across all months in the data is 1.91 for men and 0.83 for women. This means that, on average, suicide rates for men are 2.3 times higher than women during the period of study.

Fig. 3 also reveals that 2020 suicide rates for both men and women follow a similar pattern to the one discussed above: they are below previous years' levels at the beginning of the pandemic and then begin increasing until they are above previous years' levels during August-November. Importantly, women seem to have experienced a considerable increase in suicides in October 2020. To investigate changes in suicide surrounding the state of 


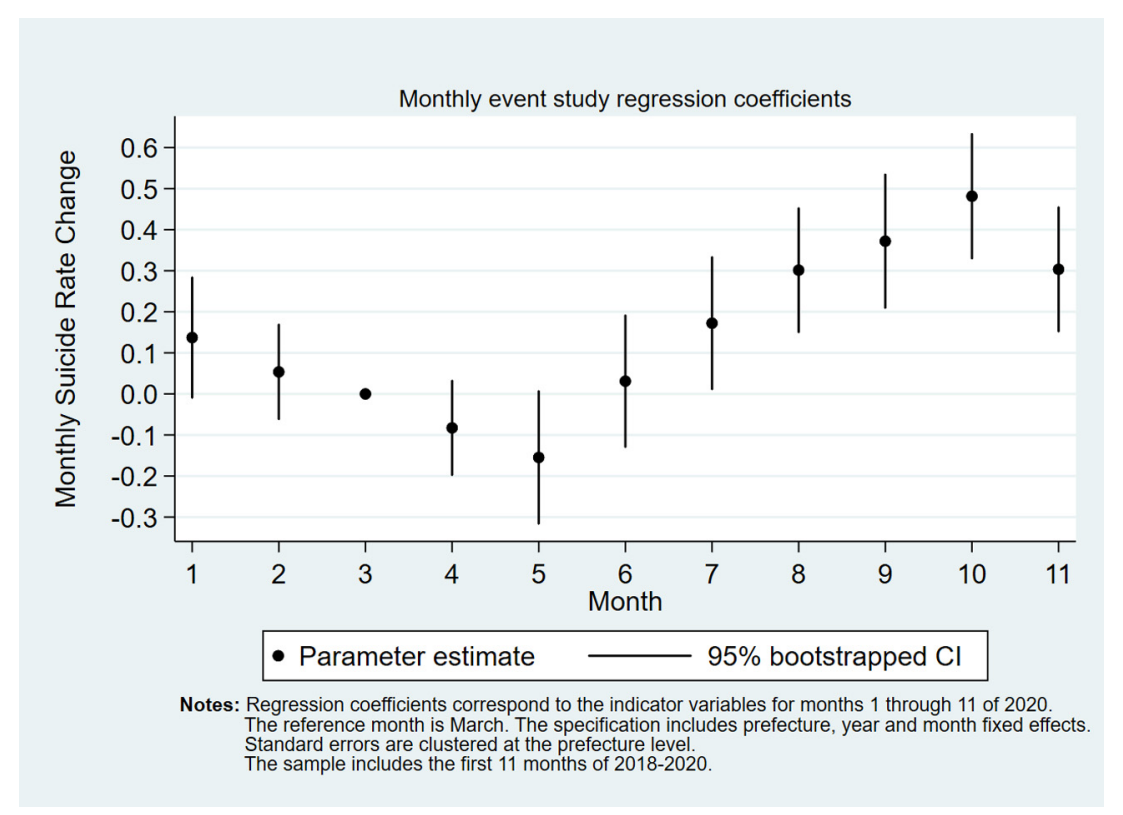

Fig. 2. Monthly changes in suicide rates in 2020 relative to 2018-2019.

Table 1

Suicide rates: Event study model coefficient estimates.

\begin{tabular}{|c|c|c|c|c|c|}
\hline & Month & $\begin{array}{l}\text { (1) } \\
\text { Prefecture- } \\
\text { Month-Year } \\
\text { Dataset }\end{array}$ & $\begin{array}{l}(2) \\
\text { Gender-Month } \\
\text { Year } \\
\text { Dataset }\end{array}$ & $\begin{array}{l}\text { (3) } \\
\text { Gender-Month- } \\
\text { Year Dataset } \\
\text { (Females Only) }\end{array}$ & $\begin{array}{l}(4) \\
\text { Gender-Month- } \\
\text { Year Dataset } \\
\text { (Males Only) }\end{array}$ \\
\hline$t=-3$ & January & $\begin{array}{l}0.137^{*} \\
(0.075)\end{array}$ & $\begin{array}{l}0.158^{* *} \\
(0.073)\end{array}$ & $\begin{array}{l}0.052 \\
(0.044)\end{array}$ & $\begin{array}{l}0.265^{* *} \\
(0.114)\end{array}$ \\
\hline$t=-2$ & February & $\begin{array}{l}0.054 \\
(0.059)\end{array}$ & $\begin{array}{l}0.021 \\
(0.039)\end{array}$ & $\begin{array}{c}-0.034 \\
(0.036)\end{array}$ & $\begin{array}{l}0.077 \\
(0.106)\end{array}$ \\
\hline$t=-1$ & March (omitted) & 0 & 0 & 0 & 0 \\
\hline$t=0$ & April & $\begin{array}{l}-0.083 \\
(0.059)\end{array}$ & $\begin{array}{l}-0.108^{\text {*** }} \\
(0.001)\end{array}$ & $\begin{array}{l}-0.110^{* * *} \\
(0.025)\end{array}$ & $\begin{array}{c}-0.107 \\
(0.123)\end{array}$ \\
\hline$t=1$ & May & $\begin{array}{l}-0.155^{*} \\
(0.083)\end{array}$ & $\begin{array}{l}-0.075^{* * *} \\
(0.008)\end{array}$ & $\begin{array}{l}-0.063^{* * *} \\
(0.009)\end{array}$ & $\begin{array}{l}-0.087 \\
(0.115)\end{array}$ \\
\hline$t=2$ & June & $\begin{array}{l}0.031 \\
(0.082)\end{array}$ & $\begin{array}{l}0.046^{* * *} \\
(0.003)\end{array}$ & $\begin{array}{l}0.050^{* * *} \\
(0.013)\end{array}$ & $\begin{array}{l}0.043 \\
(0.108)\end{array}$ \\
\hline$t=3$ & July & $\begin{array}{l}0.172^{* *} \\
(0.083)\end{array}$ & $\begin{array}{l}0.220^{* * *} \\
(0.012)\end{array}$ & $\begin{array}{l}0.238^{* * *} \\
(0.057)\end{array}$ & $\begin{array}{l}0.203 \\
(0.121)\end{array}$ \\
\hline$t=4$ & August & $\begin{array}{l}0.301^{* * *} \\
(0.077)\end{array}$ & $\begin{array}{l}0.351^{* * *} \\
(0.028)\end{array}$ & $\begin{array}{l}0.309^{* * *} \\
(0.067)\end{array}$ & $\begin{array}{l}0.392^{* * *} \\
(0.102)\end{array}$ \\
\hline$t=5$ & September & $\begin{array}{l}0.372^{* * *} \\
(0.083)\end{array}$ & $\begin{array}{l}0.283^{* * *} \\
(0.015)\end{array}$ & $\begin{array}{l}0.261^{* * *} \\
(0.016)\end{array}$ & $\begin{array}{l}0.306^{* *} \\
(0.101)\end{array}$ \\
\hline$t=6$ & October & $\begin{array}{l}0.482^{* * * *} \\
(0.078)\end{array}$ & $\begin{array}{l}0.563^{* * *} \\
(0.054)\end{array}$ & $\begin{array}{l}0.642^{* * *} \\
(0.045)\end{array}$ & $\begin{array}{l}0.485^{* *} \\
(0.192)\end{array}$ \\
\hline$t=7$ & November & $\begin{array}{l}0.303^{* * *} \\
(0.078)\end{array}$ & $\begin{array}{l}0.315^{* * *} \\
(0.051)\end{array}$ & $\begin{array}{l}0.241^{* * *} \\
(0.039)\end{array}$ & $\begin{array}{l}0.389^{* * *} \\
(0.101)\end{array}$ \\
\hline
\end{tabular}

Note: Japan declared a state of emergency in April.

${ }^{*} p<0.05$.

${ }^{* *} p<0.01$.

${ }^{* * *} p<0.001$

emergency, I use these data to estimate the following event study model:

$$
\begin{aligned}
& S R_{\text {gmy }}=\sum_{\text {month }=\text { January }}^{\text {November }} \beta_{\text {month }} * I(m=\text { month and } m \text { belongs to 2020) } \\
& +\lambda_{g}+\mu_{m}+\theta_{y}+\varepsilon_{g m y}
\end{aligned}
$$

where $S R_{g m y}$ is the monthly suicide rate for gender group $g$ in month $m$ and year $y$. I include gender, month, and year fixed effects. I estimate this model using the gender-month-year level suicide rates described above. I then estimate it again restricting the sample by gender group without the gender fixed effect.
Table 1 shows the results for both the prefecture model and the gender model.

The first column reproduces the event study estimation results using the prefecture-month-year level data. The second column presents the results using the gender-month-year level data. Taken together, the first and second columns confirm that suicide rates in Japan are increasing as the COVID-19 pandemic evolves and that June, July, and August 2020 marked a clear break when suicide rates started increasing. Importantly, the estimated coefficients also follow the same pattern across months using both datasets. 
Table 2

Suicide rates: Summary statistics by age group.

Source: Ministry of Health, Labor and Welfare of Japan.

\begin{tabular}{lllllll}
\hline & 2018 & 2019 & $2018-2019$ & 2020 & $\begin{array}{l}\text { Jan-20 } \\
\text { to } \\
\text { Jun-20 }\end{array}$ & $\begin{array}{l}\text { Jul-20 } \\
\text { to } \\
\text { Nov-20 }\end{array}$ \\
\hline Under 20 & 0.22 & 0.26 & 0.24 & 0.32 & 0.26 & 0.38 \\
& $(0.04)$ & $(0.05)$ & $(0.05)$ & $(0.08)$ & $(0.04)$ & $(0.06)$ \\
$20-29$ & 1.33 & 1.38 & 1.35 & 1.64 & 1.42 & 1.92 \\
& $(0.13)$ & $(0.14)$ & $(0.14)$ & $(0.28)$ & $(0.11)$ & $(0.17)$ \\
$30-39$ & 1.36 & 1.45 & 1.41 & 1.53 & 1.36 & 1.74 \\
& $(0.08)$ & $(0.16)$ & $(0.13)$ & $(0.27)$ & $(0.18)$ & $(0.22)$ \\
$40-49$ & 1.43 & 1.52 & 1.47 & 1.60 & 1.45 & 1.78 \\
& $(0.12)$ & $(0.09)$ & $(0.12)$ & $(0.27)$ & $(0.20)$ & $(0.22)$ \\
$50-59$ & 1.70 & 1.74 & 1.72 & 1.73 & 1.56 & 1.94 \\
& $(0.16)$ & $(0.16)$ & $(0.16)$ & $(0.24)$ & $(0.15)$ & $(0.16)$ \\
$60-69$ & 1.38 & 1.47 & 1.43 & 1.46 & 1.42 & 1.51 \\
& $(0.13)$ & $(0.18)$ & $(0.16)$ & $(0.13)$ & $(0.13)$ & $(0.12)$ \\
$70-79$ & 1.54 & 1.52 & 1.53 & 1.58 & 1.49 & 1.68 \\
& $(0.13)$ & $(0.17)$ & $(0.15)$ & $(0.14)$ & $(0.10)$ & $(0.12)$ \\
80 or older & 1.65 & 1.58 & 1.61 & 1.68 & 1.48 & 1.92 \\
& $(0.17)$ & $(0.15)$ & $(0.16)$ & $(0.24)$ & $(0.12)$ & $(0.07)$ \\
\hline
\end{tabular}

Note: Suicide rate is defined as the number of suicides per 100,000 .

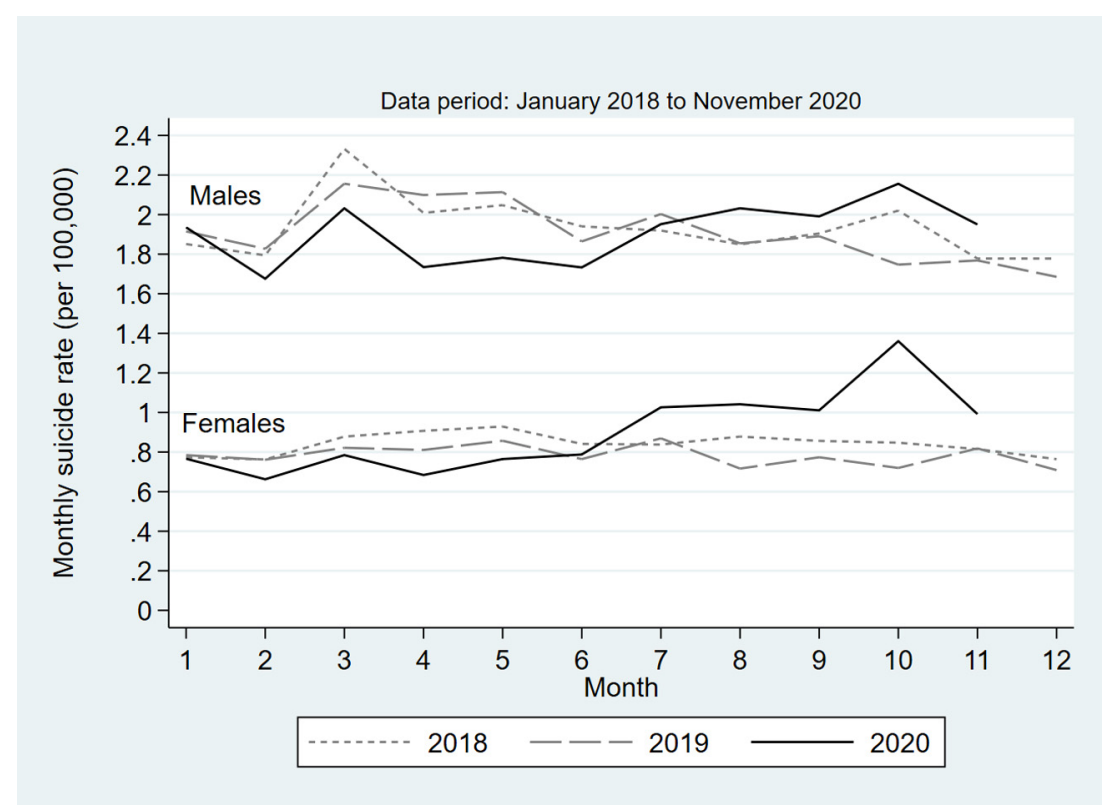

Fig. 3. Japan's monthly suicide rate average by gender group.

Table 1 also enables us to learn something about how changes in suicides for women compare to changes in suicides for men during the pandemic. The estimated coefficients suggest that in terms of changes in suicide rates, women are faring worse during the pandemic (relative to the 2018-2019 mean). For example, the average monthly suicide rate in 2018-2019 was 0.81 for women and 1.92 for men. The estimated change in suicide rate for August 2020 was 0.309 for women, representing $38.1 \%$ of their 2018-2019 mean, and 0.392 for men, representing $20.4 \%$ of their 2018-2019 mean. October 2020 was the worst month for women in terms of suicide. The estimated change for that month is 0.642 , which represents $79.2 \%$ of the 0.81 mean for women.

\section{Suicide rates by age group}

I also collected age group-month-year level data on suicide counts from January 2018 to November 2020 reported by the Ministry of Health, Labor and Welfare of Japan. I then combined them with age group-year level population estimates to compute age group-month-year level suicide rates (number of suicides per $100,000)$.

Table 2 shows that, across all age groups, the average suicide rate in 2020 was higher than the average suicide rate in 20182019. However, there is meaningful heterogeneity across age groups in terms of how much the average suicide rate changed from 2018-2019 to 2020. For example, the average suicide rate for the "Under 20" age group was 0.24 in 2018-2019 and 0.32 in 2020 , representing a $32 \%$ increase. The average suicide rate for the "20-29" age group in 2018-2019 was 1.35 and 1.64 in 2020, representing a $21.5 \%$ increase. For the " $30-39$ " and " 40 - 49" groups, there were $8.9 \%$ and $8.7 \%$ increases, respectively. However, for the rest of the age groups, the increase is notably smaller, suggesting that the increase in suicide rates was more pronounced among individuals under 30 years old. These rates suggest that in terms of suicide, younger individuals were faring worse during the pandemic (relative to the pre-pandemic 2018-2019 mean). 
Table 3

Suicide rates: Event study model coefficient estimates.

\begin{tabular}{|c|c|c|}
\hline & Month & $\begin{array}{l}\text { Age Group- } \\
\text { Month-Year } \\
\text { Dataset }\end{array}$ \\
\hline$t=-3$ & January & $\begin{array}{l}0.131 \\
(0.082)\end{array}$ \\
\hline$t=-2$ & February & $\begin{array}{l}-0.014 \\
(0.057)\end{array}$ \\
\hline$t=-1$ & March (omitted) & 0 \\
\hline$t=0$ & April & $\begin{array}{l}-0.151^{* *} \\
(0.064)\end{array}$ \\
\hline$t=1$ & May & $\begin{array}{l}-0.102^{*} \\
(0.057)\end{array}$ \\
\hline$t=2$ & June & $\begin{array}{l}0.014 \\
(0.065)\end{array}$ \\
\hline$t=3$ & July & $\begin{array}{l}0.201^{* * *} \\
(0.07)\end{array}$ \\
\hline$t=4$ & August & $\begin{array}{l}0.337^{* * *} \\
(0.052)\end{array}$ \\
\hline$t=5$ & September & $\begin{array}{l}0.303^{* * *} \\
(0.083)\end{array}$ \\
\hline$t=6$ & October & $\begin{array}{l}0.561^{* * *} \\
(0.077)\end{array}$ \\
\hline$t=7$ & November & $\begin{array}{l}0.315^{* * *} \\
(0.05)\end{array}$ \\
\hline
\end{tabular}

Note: Japan declared a state of emergency in April.

${ }^{*} p<0.05$.

${ }^{* *} p<0.01$

${ }^{* * *} p<0.001$.

Table 2 also shows the average suicide rates across age groups for the first and second half of 2020. Average suicide rates were higher in the second half across all age groups. This is consistent with our previous finding: suicides rates started increasing meaningfully in June-July, with an important increase in October. The change in average suicide rates from the first to the second half is also bigger for individuals under 30 years old.

Finally, I also use these data to estimate the following event study model:

$$
\begin{aligned}
& S R_{\text {amy }}=\sum_{\text {month }=\text { January }}^{\text {November }} \beta_{\text {month }} * I(m=\text { month and } m \text { belongs to 2020) } \\
& +\lambda_{a}+\mu_{m}+\theta_{y}+\varepsilon_{g m y}
\end{aligned}
$$

where $S R_{a m y}$ is the monthly suicide rate for age group $a$ in month $m$ and year $y$. I include age group, month, and year fixed effects. Table 3 shows the results. The estimated coefficients confirm the previously described patterns.

\section{Conclusion}

This paper studies suicides in Japan before and during the COVID-19 pandemic. It uses an event study design to quantify changes in suicide rates surrounding Japan's COVID-19 state of emergency and finds that suicides started increasing meaningfully in June-July 2020. It also finds that changes in suicide rates were higher for women and that the increase in suicide rates was more pronounced among individuals under 30 years old. Further research is needed to learn more about the mechanisms behind the documented increase in suicides.

The paper also suggests that we should be attentive to how suicide rates and other causes of death evolve in Japan for the remainder of the ongoing pandemic. I found that suicides declined in April and May 2020. In addition, the 2020 lockdown in Japan led to a $12.7 \%$ decline in violent crime victimization rates per 100,000 people (Shen et al., 2021), and there is no evidence that the absolute number of fatal motor vehicle collisions increased in Japan (Inada et al., 2021). Both studies use data ending in May 2020. However, I also show that suicides started increasing meaningfully in June-July 2020. My paper therefore suggests the importance of continuing to monitor death counts associated with different causes of death in the future.

\section{Declaration of competing interest}

The author declares that he has no known competing financial interests or personal relationships that could have appeared to influence the work reported in this paper.

\section{Acknowledgement}

I am grateful for comments and suggestions that substantially improved the article from the Editor (Costas Meghir) and an anonymous referee. I also thank Liz Neyens for her helpful comments.

\section{Appendix A. Supplementary data}

Supplementary material related to this article can be found online at https://doi.org/10.1016/j.econlet.2021.110014.

\section{References}

Becker, S., Woesmann, L., 2018. Social cohesion, religious beliefs, and the effect of protestantism on suicide. Rev. Econ. Stat. 100 (3), 377-391.

Calderon-Anyosa, R., Bilal, U., Kaufmam, J.S., 2021. Variation in non-external and external causes of death in peru in relation to the COVID-19 lockdown. The Yale J. Biol. Med 94 (1), 23-40.

Campaniello, N., Diasakos, T., Mastrobuoni, G., 2017. Rationalizable suicides: Evidence from changes in inmates' expected length of sentence. J. Eur. Econom. Assoc. 114 (33), 8746-8751.

Christian, C., Hensel, L., Roth, C., 2019. Income shocks and suicides: Causal evidence from Indonesia. Rev. Econ. Stat. 101 (5), 905-920.

Cutler, D., Glaeser, E., Norberg, K., 2001. Explaining the rise in youth suicide. In: Gruber, Jonathan (Ed.), Risky Behavior Among Youths: An Economic Analysis. University of Chicago Press, Chicago, pp. 219-270.

Daly, M., Wilson, D., Johnson, N., 2013. Relative status and well-being: Evidence from US suicide deaths. Rev. Econ. Stat. 95 (5), 1480-1500.

Dow, W., Godoy, A., Lowenstein, C., Reich, M., 2020. Can economic policies reduce deaths of despair?. In: NBER Working Paper 25787.

Faust, J.S., Du, C., Dickerson Mayes, K., Li, S., Lin, Z., Barnett, M., Krumholz, H., 2021a. Mortality from drug overdoses, homicides, unintentional injuries, motor vehicle crashes, and suicides during the pandemic, March-2020. JAMA 326 (1), 84-86.

Faust, J.S., Shah, S., Du, C., Li, S., Lin, Z., Krumholz, H., 2021b. Suicide deaths during the COVID-19 stay-at-home advisory in Massachusetts, March to 2020. JAMA Network Open.

Inada, H., Ashraf, L., Campbell, S., 2021. COVID-19 lockdown and fatal motor vehicle collisions due to speed-related traffic violations in Japan: a time-series study. Injury Prevention 27 (1), 98-100.

Lenhart, O., 2019. The effects of state-level earned income tax on credits on suicides. Health Econ 28 (12), 1476-1482.

Ludwig, J., Marcotte, D., Norberg, K., 2009. Anti-depressants and suicide. J. Health Econ. 28 (3), 659-676.

Shen, Y., Fu, R., Noguchi, H., 2021. COVID-19's lockdown and crime victimization: The state of emergency under the abe administration. Asian Econ. Policy Rev 16 (2), 327-348.

Stevenson, B., Wolfers, J., 2006. Bargaining in the shadow of the law: Divorce laws and family distress. Q. J. Econ. 12 (121), 267-288.

Vandoros, S., Theodorikakou, O., Katsadoos, K., Zafeiropoulou, D., Kawachi, I., 2020. No evidence of increase in suicide in Greece during the first wave of Covid-19. In: medRxiv preprint.

World Health Organization, 2019. Suicide in the World. Global Health Estimates. WHO, Geneva.

\section{Further reading}

Yabe, T., Tsubouchi, K., Fujiwara, N., Wada, T., Sekimoto, Y., Ukkusuri, S., 2020. Non-compulsory measures sufficiently reduced human mobility in Tokyo during the COVID-19 epidemic. Nature 10, 18053, Scientific Reports.

Apple, 2020. Mobility Trends Reports, available at https://covid19.apple.com/ mobility. 